\title{
Perception of First Year Medical Students towards Newer Methods of Teaching in Anatomy
}

\author{
Dr. Asharani SK ${ }^{1}$, Dr. Ajay Ningaiah ${ }^{2 *}$
}

${ }^{1}$ Associate Professor, Department of Anatomy Adichunchanagiri Institute of Medical Sciences, B.G Nagara, Karnataka, India

${ }^{2}$ Assistant Professor, Department of Anatomy Adichunchanagiri Institute of Medical Sciences, Mandya Dist, B.G Nagara, Karnataka, India

\author{
DOI: $10.36348 /$ sijap.2019.v02i11.007 \\ | Received: 11.11.2019| Accepted: 19.11.2019| Published: 28.11.2019 \\ *Corresponding author: Dr. Ajay Ningaiah
}

\section{Abstract}

Background: Teaching is a process of imparting a corpus of knowledge to a group of individuals. Teaching methods in Anatomy include dissection by students, demonstration of prosected specimens, the use of models and computer animations, instructional teaching, study of living anatomy by clinical examination and radiological techniques. The appropriateness of a teaching method to arrive at the desired specific learning outcomes is governed by the concept known as "fitness for purpose". Aim: To gauge the perception of first year medical students regarding the newer teaching methods. Materials and Methods: The Questionnaire based study was conducted on 150 first year medical students of Adichunchanagiri Institute of medical sciences, B G Nagara. The data obtained was statistically analyzed. Results: $26.7 \%$ of the participants were of the opinion that newer methods of teaching will help in learning anatomy, whereas $67.3 \%$ felt that older methods are effective in teaching. Conclusion: Effective methods of teaching and learning will improve knowledge retention of basic science subjects like anatomy. A sound knowledge in the basic sciences is very valuable in clinical settings; it allows the students to understand the association between presenting clinical features and diagnoses.

Keywords: Perception, Students, Newer, Teaching methods, Anatomy, Dissection.

Copyright @ 2019: This is an open-access article distributed under the terms of the Creative Commons Attribution license which permits unrestricted use, distribution, and reproduction in any medium for non-commercial use (NonCommercial, or CC-BY-NC) provided the original author and source are credited.

\section{INTRODUCTION}

Lecture class is the most common and universally accepted way of teaching. Most of the lectures are still taken with chalk and board; however recently audio visual aids are being used along with it[2]. Although small group teaching is the most effective means of teaching, it is difficult to carry out because of the disparity in the faculty student ratio.

Anatomy is considered as the most challenging and important subject in the preclinical phase and mastery over it is essential for laying a strong foundation for clinical excellence. Didactic lectures and cadaveric dissections have been the traditional mainstays in the teaching of Anatomy

Recent advances in technology has thrown up newer tools to supplement traditional teaching methods like plastinated models, digital imaging techniques, web-based study materials, 3D visuals aids etc. These tools have been adopted to make the learning of anatomy easier and more interesting. In the current era of teaching which encompasses the "competency based curriculum", more importance is being given to integrate \& clinically relevant, problem based, student centered teaching and learning [1].

The student's participation can be upgraded with the help of e learning technologies. New and emerging technologies are now widely recognized and utilized by many universities across the country [7]. Judicious use of newer technologies in conjunction with traditional methods will aid in the better understanding of anatomy which consequently, will boost the educational values [1].

Feedback by the students is a sound basis for improving and modifying medical education. Feedback can help to recognize areas of strength and weakness in teaching methods. Evaluation of teaching effectiveness by the students will improve the quality of teaching if assessed appropriately [7].

The purpose of the study was to know their perception towards newer methods of teaching 
encountered with the intention of comparing the effectiveness of different teaching methods.

\section{OBJECTIVES}

This study was undertaken to gauge the perception of first year medical students towards Newer Methods of Teaching

\section{MATERIALS AND METHOD}

The study was done among 150 first year medical students of Adichunchanagiri Institute of Medical Sciences, Mandya district. The full strength participation of the subjects was ensured. The study questionnaire was administered to students after obtaining their written consent which included information regarding their perception towards newer methods of Teaching. The ethical committee approval was taken prior to commencement of the study. The data was analyzed statistically. The study was of cross sectional type which included details of the subjects collected at one point of time in the study period. The information obtained was coded and entered in a excel sheet and analyzed. The suitable percentage and proportions were calculated in interpretation of the result obtained.

\section{RESULTS}

$26.7 \%$ of students felt newer methods of teaching will facilitate learning Anatomy but $67.3 \%$ students felt older methods are effective in teaching and $6 \%$ students were neutral in their opinion.

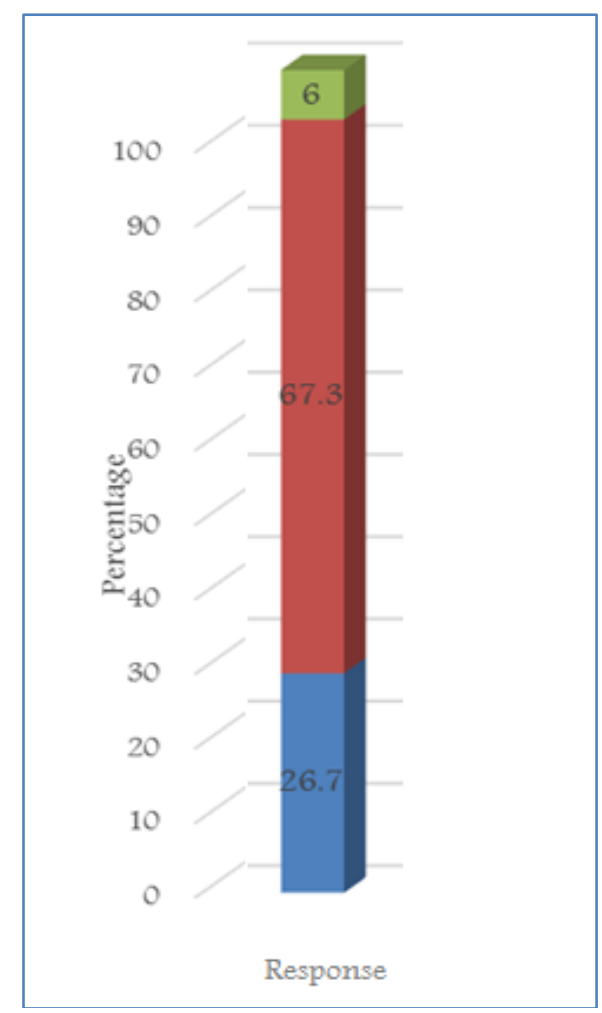

Fig-01: Bar diagram showing the response of students towards newer methods of teaching

\section{DISCUSSION}

Anatomy remains a core topic for first year medical students. The method of teaching has changed over a period of time with the advent of new technologies in education [1]. Merging old and new types of teaching methods offers learners a great opportunity to enhance their efficiency as well as for teachers to maintain active student participation [7]. Vertical and horizontal integration are now a part of new competency based curriculum which helps students in better understanding of the subject.

- Rokade SA \& Bahetee BH, analyzed the opinion of students regarding power point presentations versus chalk and board in a lecture class and concluded that the chalk and Board method was more interesting [2]. Few other studies also concluded that it's not the teaching method but the teacher who utilizes it will decide the efficacy of teaching [8].

- According to Hassanzadeh G, Hassanpoor N, majority of students felt that dissection hall teaching is preferable followed by audio visual aids, conventional chalk and board methods [9].

- The study done by Wyk VJ and Rennie CO reported a positive experience $(70 \%)$ during anatomical dissection in terms of visual and clinical application in understanding the subject. The study also said that dissection is the most preferred method compared to newer PBL [10].

- A study done by Gilbody J, et al. showed the use of cadaveric workshops in higher surgical training. According to the study, there is no proper data to say that how cadaveric workshops are beneficial in training the surgeons. But definitely it can be used as one of the training tools in postgraduate education [4].

In a study done by Agnihotri G and Sagoo MG, there were no statistically significant differences in the rate of anxiety between experimental and control group. The students should be prepared mentally and emotionally before entering the dissection room so as to involve in dissection [5].

A study done by Jaiswal R, Sathe $\mathrm{S}$, et al. on the perception of students on methods of anatomy teaching and assessment demonstrated that conventional methods of teaching like chalk and board as well as dissection hall teaching are the best approaches for teaching and learning anatomy. The study also concluded that unit or topic test is the preferred method of assessment [3].

Most of the students consider dissection as the best teaching method but very few will 
actually involve in doing it[6]. The overall findings suggest that lecture and dissection methods remain as a gold standard methods of teaching. However newer methods can aid to it.

Introduction of new technological innovations necessitates training and empowering staff in the use of these technologies for teaching and learning [7].

\section{CONCLUSION}

As learning and teaching processes change over the years, students and teachers can choose the most suitable method to enhance and convey the knowledge of anatomy. Cadaveric dissection has proven to be more effective than its simulated counterparts in the retention of information. The combination of newer methods with conventional teaching strengthens the students' understanding of anatomy, a subject that is difficult to master. However, traditional methods (dissection) still remain the most powerful means of learning anatomy compared to newer methods.

Effective methods of teaching and learning will improve knowledge retention of basic science subjects like anatomy. A sound knowledge in the basic sciences is very valuable in clinical settings; it allows the students to understand the association between presenting clinical features and diagnoses.

\section{ACKNOWLEDGEMENT}

The authors thank Adichunchanagiri Institute of Medical Sciences, B G Nagar, Mandya for providing the necessary support in conducting this study. We also thank Dr Shashikantha S K, Assistant professor, Department of Community Medicine for helping in analyzing the data.

\section{REFERENCES}

1. Bandyopadhyay, R., \& Biswas, R. (2017). Students' Perception and Attitude on Methods of Anatomy Teaching in a Medical College of West Bengal, India. Journal of clinical and diagnostic research: JCDR, 11(9), AC10.

2. Rokade, S. A., \& Bahetee, B. H. (2013). Shall we teach anatomy with chalk and board or power point presentations. An analysis of Indian student's perspectives and performance. Sch J App Med Sci, 1(6), 837-42.

3. Jaiswal, R., Sathe, S., Gajbhiye, V., \& Sathe, R. (2015). Students perception on methods of anatomy teaching and assessment. Int $J$ Anat Res, 3(2), 1103-08.

4. Gilbody, J., Prasthofer, A. W., Ho, K., \& Costa, M. L. (2011). The use and effectiveness of cadaveric workshops in higher surgical training: a systematic review. The Annals of The Royal College of Surgeons of England, 93(5), 347-352.

5. Agnihotri, G., \& Sagoo, M. G. (2010). Reactions of first year Indian medical students to the dissection hall experience. NJIRM, 1(4), 4-9.

6. Karau, P. B., Wamachi, A., Ndede, K., Mwamisi, J., \& Ndege, P. (2014). Per

7. Govender, S. (2015). Students' perceptions of teaching methods used at South African Higher Education Institutions: part 1. South African Journal of Higher Education, 29(3), 23-41.

8. Prasad, S., Roy, B., \& Smith, M. (2000). The art and science of presentation: electronic presentations. Journal of postgraduate medicine, 46(3), 193.

9. Hassanzadeh, G., Hassanpoor, N., Jalali, A., Hassanzadeh, N., Jafari, M., \& Panahi, N. (2012). Teaching anatomy: viewpoints of Iranian anatomists. Thrita, 1(2), 62-6.

10. Van Wyk, J., Rennie, C. O., VAN WYK, J., \& CO, R. (2015). Learning anatomy through dissection: Perceptions of a diverse medical student cohort. Int j morphol, 33(01), 89-95. 